\title{
El Legado del Constituyente de Querétaro: Avances y AgENDA
}

1 Introducción. 2 Constitución y constitucionalismo. Una necesaria distinción inicial. 3 Una mirada al constitucionalismo mexicano de 1917 desde la teoría constitucional contemporánea. 4 Las edades del constitucionalismo mexicano de 1917. 5 La mirada política. Las reformas de mayor importancia por periodos políticos del constitucionalismo mexicano. 6 La consolidación del constitucionalismo mexicano. $7 \mathrm{La}$ experiencia de un presidencialismo sobresaliente con partido hegemónico. $8 \mathrm{El}$ periodo democrático de la Constitución Mexicana. De 1977 a la actualidad. 9 Breve recapitulación. 9.1 Transformación desde un constitucionalismo predominantemente institucional, político, hacia uno que se ha centrado más en los derechos humanos. 9.2 Cambio de un constitucionalismo volcado al interior a otro vinculado al contexto internacional. 9.3 Mutación de un régimen autoritario con tendencias corporativistas a otro democrático. 9.4 Tendencia clara a un centralismo normativo. 9.5 Tránsito desde un constitucionalismo orientado al control de la economía hacia uno de contenido neoliberal. 9.6 Prolijidad en los contenidos de la constitución. 10 Algunas apreciaciones finales. Referencias.

\section{RESUMEN}

Este ensayo aborda el análisis de la evolución del constitucionalismo mexicano al cumplirse cien años de vigencia de la Constitución Mexicana, que fue emitida en la Ciudad de Querétaro el 5 de febrero de 1917. El ensayo sostiene que la longevidad de esta Constitución se debe a la intensa actividad de los órganos legislativos mexicanos que ejercen la función de reforma constitucional, lo que ha aportado una gran plasticidad al texto escrito, favoreciendo la adaptación entre la norma fundamental y la evolución de la sociedad mexicana. Al mismo tiempo, el desarrollo del constitucionalismo mexicano, que históricamente había privilegiado la mirada política propia de los mencionados órganos legislativos, ha arribado a un reforzamiento del entendimiento jurídico de la Constitución. Esto conduce a admitir -en un nuevo entendimiento del constitucionalismo mexicano- la coexistencia entre el tradicional entendimiento político, que actúa a través de adaptaciones formales al texto constitucional, junto a una creciente presencia de los órganos judiciales que imprimen un sello claramente jurídico a la constitución mexicana, creando con ello un entorno de diálogos constitucionales entre las funciones de reforma constitucional y el control de la regularidad constitucional.

Palabras clave: Historia Jurídica. Derecho Constitucional. Reforma Constitucional. Constitución Mexicana. Federalismo. Control Constitucional.

* Licenciado en Derecho por la UNAM y Doctor en Derecho por la Universidad Complutense de Madrid. Investigador Visitante en Yale Law School y en la Universidad del País Vasco. E-mail: <lraigosa@itam. $\mathrm{mx}>$. http://orcid.org/0000-0001-5617-1181 


\section{INTRODUCCIÓN}

Para acometer el estudio a que el título convoca, que habrá de ser breve por las necesidades de la ocasión, conviene anticipar que se trata de un ensayo que aborda el tema con una visión diacrónica, pero que no puede olvidar las circunstancias que le eran propias al momento histórico de la creación de esta constitución, aunque se apunte a su análisis con criterios propios de teorías contemporáneas, ajenas a aquellos momentos.

El objetivo de este ensayo es ofrecer una descripción de la mirada política del constitucionalismo mexicano, la que ha aportado el órgano revisor de la Constitución en esos cien años. Se sostiene la tesis de que este órgano conservó durante muchas décadas una clara preponderancia de la facultad interpretativa del constitucionalismo, esto es, de la forma en que se escribe y reescribe la constitución, en que se entiende y se aplica, en la que se la vive. Es la interpretación política del constitucionalismo mexicano. No fue la única perspectiva posible, como es natural. Presente ha estado también la acción interpretativa de los órganos custodios de la constitución, los jueces. Sin embargo, nuestra historia evidencia que la importancia de esta otra perspectiva de interpretación, la mirada jurídica, no asume protagonismo sino hasta fines del siglo XX.

El proceso de escrituración de tramos normativos de la Constitución mexicana ha sido muy intenso. Hemos identificado 701 reformas a la Constitución de 1917 en los cien años de vida cumplidos el 5 de febrero de 2017. Damos cuenta de ello y de la marcha de esos cambios, cada vez más intensa conforme avanza el tiempo. Los cambios son el resultado formal de la interpretación política del constitucionalismo mexicano. Incluso la gran evolución desde ese constitucionalismo centralizado en lo político hacia uno con énfasis en lo jurídico y en los derechos humanos es también producto de un proceso formal de cambio constitucional. Sin embargo, hay que observar estos fenómenos desde el constitucionalismo, no sólo desde la constitución para encontrar mejores explicaciones a la evolución de nuestra historia constitucional centenaria.

Puede afirmarse que el legado de nuestros padres fundadores de 1917 contiene tanto la posibilidad de ambas miradas e interpretaciones constitucionales, la política y la jurídica que hoy están en posición de diálogo, como la capacidad evolutiva de nuestra constitución, cuyo enorme dinamismo ha permitido adaptaciones a una sociedad compleja, con fuertes desequilibrios sociales y económicos y que paradójicamente se muestra a veces en veloz transformación y en otras ocasiones aferrada a tradiciones.

Estas posiciones iniciales nos conducen a construir el ensayo en las siguientes partes. En primer lugar revisaremos una importante distinción entre los conceptos constitución y constitucionalismo, útil para desarrollar los elementos del análisis del legado de nuestros constituyentes de 1917. Seguidamente intentaremos un análisis de ese constitucionalismo desde una óptica teórica actual. En tercer lugar consideraremos una propuesta de explicación de la evolución del constitucionalismo mexicano entre 1917 y 2017, tomando en cuenta criterios puntuales, particularmente el predominio, por muchas décadas, de una visión política 
frente a otra jurídica del constitucionalismo mexicano, y el abandono de esta preeminencia hacia una amalgama interesante de perspectivas del constitucionalismo mexicano en donde política y derecho, a través de juegos institucionales, se dan la mano. En cuarto lugar, damos cuenta del desarrollo centenario de lo que hemos denominado la mirada política del constitucionalismo, recordando muchos de los actos de reforma a la Constitución, producto del ejercicio interpretativo del revisor constitucional, exponiendo finalmente algunas inquietudes concluyentes.

\section{CONSTITUCIÓN Y CONSTITUCIONALISMO. UNA NECESARIA DISTIN- CIÓN INICIAL}

Sutil e importante es la diferencia que suele encontrarse en la literatura especializada en teoría constitucional entre las concepciones constitución y constitucionalismo. La primera, afirman generalmente los autores que abordan esta distinción, refiere al texto escrito que lleva el nombre constitución, ya sea el documento original o bien el que alberga en algún momento concreto también nuevas o reconstruidas disposiciones. La voz constitucionalismo, en cambio, da cobijo a una riqueza semántica importante pues los contenidos definitorios de esta voz son aportados a partir de diferentes visiones de la experiencia constitucional. Por ejemplo, Josep Aguiló sostiene que frente al estudio de los textos constitucionales, existe la opción más rica y compleja que sugiere abordar el conocimiento de una constitución a través de las lentes teóricas que proponen una cierta lectura o una orientación específica en la interpretación de dichos textos, y con ello se genera una diferencia conceptual entre texto constitucional y alguna teoría que señala o aconseja una cierta mirada -una específica lectura- de la constitución, produciendo distintas concepciones de constitución; tal distinción es el efecto del acento que ponen las teorías en ciertas propiedades de los textos normativos constitucionales frente a otras prioridades, especialmente cuando existe incertidumbre o conflicto en su estudio o aplicación. ${ }^{1}$ De conformidad con esta postura, no se afirma, por ejemplo, que una constitución se limita a cumplir una función garantista mientras que otra asume una normativista o que alguna constitución fija procedimientos mientras que otra lo que hace es establecer valores. El autor sostiene que todas las constituciones asumen esas diversas propiedades, pero las diversas teorías ponen el énfasis en alguna de esas características frente a las demás, particularmente en casos de duda o conflicto, generando así posiciones constitucionales diversas. Por tanto, conforme a esta postura, la diferencia se expresa entre el texto -la constitución- y las diferentes teorías que pueden construirse para su conocimiento -constitucionalismo-.

Aguda es también la distinción que Manuel Aragón formula entre constitución y constitucionalismo (ARAGÓN REYES, 1998). En su estudio del constitucionalismo actual como paradigma, el profesor madrileño convoca a la reflexión sobre las condiciones o características que - en su opinión - llenan de significado la voz "constitucionalismo". Aquí también constitución es la voz que denota un texto jurídico que lleva ese nombre. Pero, 
de nuevo, como en el caso anterior, la riqueza del tema y del problema de la constitución se traslada al constitucionalismo, aunque aquí texto, teoría y práctica jurídicos son los ingredientes que integran una poderosa amalgama conceptual que permite comprender la riqueza de la experiencia constitucional de nuestros días.

Varias y complejas son las características que dan significado al constitucionalismo, en los términos aportados por el profesor Aragón. Así, destaca la existencia de controles jurídicos orientados a proteger la constitución, con énfasis en los controles judiciales. No es menor tampoco la importancia de la necesaria adaptabilidad de los textos constitucionales a las condiciones sociales propias de diferentes situaciones y momentos, ya sea a través de su expresión formal realizada por la vía de las reformas constitucionales expresas cumplidas por el órgano competente para llevarlas a cabo, o por la vía de las interpretaciones construidas por los órganos jurisdiccionales en el ejercicio de sus funciones de control constitucional. Pero el constitucionalismo no se acaba en el ejercicio de las atribuciones que las instituciones constitucionales ejercen, como son los tribunales o el órgano reformador constitucional, pues no se explica a cabalidad si se abandona el impacto que el estudio profesional de la constitución supone, particularmente de las teorías orientadas a su comprensión, a la formación de un saber jurídico que soporte el entendimiento del fenómeno constitucionalismo como una forma de construir protecciones jurídicas protectoras de los derechos humanos de los gobernados. De la mano de estas construcciones teóricas el constitucionalismo deriva en la creación de una cultura constitucional y un saber jurídico específico que dota de sentido y hace fluir la vivencia de este constitucionalismo.

A las condiciones definitorias anteriores se suma el fértil campo de la adecuación entre los constitucionalismos nacionales y el creciente fenómeno de los ordenamientos internacionales protectores de derechos humanos, por la vía del control de convencionalidad. Finalmente, el profesor Aragón suma un elemento esencial para el éxito del constitucionalismo, consistente en la aceptación popular de las constituciones, pues sin esta condición -la eficacia normativa- puede verse limitada la vida de un texto o una vivencia constitucional concreta. Así las cosas, puede concluirse que el constitucionalismo hace soplar los vientos hacia una constitucionalización del derecho, de la política, de la sociedad, y también hacia una internacionalización del constitucionalismo.

La invocación de las posiciones teóricas señaladas -aunque necesariamente muy breve- ofrece la ocasión oportuna para revisar los extremos que el título de este ensayo apunta. Sólo el concepto de constitucionalismo, por la exigencia y diversidad de elementos que lo componen, resulta suficientemente fecundo para extraer explicaciones que aporten sentido al estudio de nuestra historia constitucional secular, cuando las preguntas convocan a reflexionar sobre los cambios constitucionales o del constitucionalismo mexicano, que han sido, o los que habría que proponer, al cumplirse un siglo de la expedición de la Carta Fundamental de 1917. 


\section{UNA MIRADA AL CONSTITUCIONALISMO MEXICANO DE 1917 DESDE LA TEORÍA CONSTITUCIONAL CONTEMPORÁNEA}

La construcción de un constitucionalismo alrededor de una experiencia constitucional concreta, nos sugieren las teorías recién expuestas, convoca a la revisión de diversas cuestiones, de varios elementos, aunque el énfasis recaiga en uno sobre los demás. Volvamos la mirada a la experiencia constitucional mexicana de 1916-1917. ¿Cómo se ha construido el conjunto de disposiciones que llamamos constitución, pero especialmente, cómo se le ha entendido y se le ha vivido, cómo se le ha hecho asociarse con la sociedad mexicana, su cultura, su economía o las vidas de sus integrantes de 1917 al día de hoy? Adelantamos que de la historia del proceso creador de esta carta fundamental es posible rescatar una postura de constitucionalismo compuesto por una doble vertiente, una que mira al derecho y otra que observa a lo político, y esto no es una novedad en el contexto de los constitucionalismos. A ello se suman las interpretaciones aportadas por la comunidad académica y la cultura constitucional que anima la vivencia del constitucionalismo mexicano.

Es verdad que en el texto del discurso del Primer Jefe Venustiano Carranza con el que presentó su proyecto de constitución al Congreso constituyente se aprecia una posición constitucional que defendía la necesidad de perfeccionar el texto de 1857, y también lo es que el nombre de su proyecto evidencia ese propósito político o ideal constitucional. La visión del principal líder del bando triunfante de la Revolución mexicana no abandonaba una posición liberal, que en lo esencial era consecuente con la visión constitucional de mayor arraigo del siglo XIX. Asimismo, es verdad que Carranza también asumió una posición crítica frente al constitucionalismo del '57, por haber sido impulsor de instituciones que asombrosamente no consideraron al pueblo para el cual había sido creada la gran constitución liberal de mediados del siglo XIX, tal y como, apenas cuatro años antes, lo había asentado Emilio Rabasa en su severo enjuiciamiento emitido en 1912 en su gran obra La constitución y la dictadura, al afirmar metafóricamente que la de 1857 era una constitución que podía ser comparada con un traje confeccionado maravillosamente, pero que no había tomado en consideración el cuerpo que lo iba a usar. ${ }^{2}$

Consecuente con su postura, Carranza propuso reformas importantes a la Carta de 1857, entre las que cabe recordar algunas como la incorporación del ministerio público en el proceso penal, el cual fue entendido como una institución que permitiría superar las terribles injusticias que eran resultado del sistema penal inquisitorio que imperaba desde la época de domino novohispano y habían continuado durante todo el largo siglo XIX, la limitación de las sanciones por faltas administrativas, el establecimiento de reglas para reducir los juicios del orden penal, y otras cuestiones más que, en la visión del Primer Jefe Carranza, impactaban en el campo de los derechos fundamentales. Asimismo, le parecía indispensable avanzar en el perfeccionamiento del juicio de amparo, aunque consideró correcto mantener la vertiente del amparo contra las sentencias que fueren emitidas en los casos de juicios de los órdenes jurídicos locales, pero por razones de tipo político, esto es, para contrarrestar el poder de los 
gobernadores de las distintas entidades federativas sobre la impartición de justicia en sus respectivos estados.

En el ámbito de las instituciones, en cambio, si bien el proyecto tocó otros temas como la incorporación de disposiciones reguladores del municipio como entidad política y de administración, el discurso de Carranza se centró en la necesidad de fortalecer al Poder Ejecutivo. En consecuencia, argumentó en contra de la posibilidad de incorporar normas constitucionales orientadas a construir un régimen parlamentario de gobierno, también suprimió la vicepresidencia para evitar la repetición de algunas muy lamentables experiencias en la historia política mexicana como consecuencia de las ambiciones políticas insatisfechas de ciertos vicepresidentes, y mantuvo la prohibición de la reelección, que, por cierto, ya había sido suprimida del texto de 1857 desde 1912, por el impulso de una reforma constitucional durante la presidencia de Francisco I. Madero. ${ }^{3}$

Sin embargo, la actitud personal de Carranza y su posición constitucional no favorecieron la incorporación de disposiciones constitucionales concretas orientadas a proteger a la masa de mexicanos pobres y explotados en el campo y en las establecimientos de trabajo, pues sólo tímidamente propuso la facultad del Congreso para legislar en materia de trabajo, y consideró la necesidad de regular constitucionalmente la figura jurídica de la expropiación de la propiedad. ${ }^{4}$

Por otra parte, también es cierto que la visión o tesis triunfante del constitucionalismo de 1917 no fue la del Primer Jefe Carranza sino la de los diputados constituyentes radicales -que contaban con el apoyo del general Álvaro Obregón, menos temeroso que Carranza ante la posible creación de organizaciones de trabajadores y campesinos, que fueran el resultado del otorgamiento de reglas protectoras constitucionales para estos grupos sociales-, ${ }^{5}$ quienes con energía e inteligencia impulsaron un proyecto de constitución diverso, con importantes contenidos originales, que albergaba la teoría constitucional que le dio la peculiar fisonomía definitiva de constitución social.

¿Cuál fue, pues, la teoría constitucional que forma parte sustancial del constitucionalismo mexicano en 1917? Desde la perspectiva de filosofía política, una teoría de un constitucionalismo novedoso, social, protector no sólo del individuo en cuanto titular de derechos por tener la condición de ser humano, como fue la tesis central del constituyente de 1857, sino también uno protector de los miembros de las clases que habían sido desprotegidas y explotadas como consecuencia de la filosofía liberal que arropó el constitucionalismo de 1857. Un constitucionalismo no ortodoxo, que no se podía limitar a construir un texto constitucional acorde con los cánones de la tradición constitucional vigente, puesto que era de mayor importancia admitir el carácter reivindicatorio del movimiento armado y la propia legitimidad que el triunfo con las armas le había otorgado al bando victorioso que discutía el proyecto constitucional. ${ }^{6}$ Por ende, el constitucionalismo propio de la constitución de 1917 es uno social.

Por otro lado, en un plano que en primera instancia puede considerarse original, frente al liberalismo del siglo XIX, pero que, como ahora se recordará, extraía su savia 
legitimadora en muy lejanos orígenes de carácter cristiano, el constitucionalismo de 1917 tuvo otra faceta social reivindicadora de los mexicanos trabajadores del campo. Evocamos aquí las disposiciones normadoras de los derechos de propiedad incorporadas en el artículo 27 constitucional. La condición singular de la regulación del derecho de propiedad de esta Constitución estribó en la incorporación de la tesis de la propiedad originaria de la nación de las tierras y aguas. Protagonistas en el proceso de creación de este artículo, como lo fue Andrés Molina Enríquez, asesor de la comisión de constitución encargada de elaborar el proyecto de artículo 27 y el ingeniero Pastor Rouaix, el diputado constituyente que más influyó en la confección del artículo 27 constitucional (ROUAIX, 1960), defendieron la tesis de que la idea que inspiró esta regla de nuestro constitucionalismo se encuentra en el régimen jurídico de los orígenes de la Nueva España, en especial en las bulas papales emitidas por el pontífice Alejandro VI llamadas bulas alejandrinas, que otorgaba a los monarcas españoles el derecho original de propiedad de tierras, montes, minas, aguas. La tesis de la propiedad original a que se referían estos dos protagonistas de la historia revolucionaria mexicana, en la época de la conquista recibía el nombre de teoría de la teocracia pontifical. " "El derecho de propiedad primordial de la Nación sobre todo el territorio nacional existía antes en el rey de España [...]", decía Molina Enríquez, y el ingeniero Rouaix también afirmaba que "El Monarca español quedó investido con los derechos de propiedad de las tierras, de las aguas, de los minerales y de los jugos de la tierra y por eso fue el único que estaba autorizado para ceder el usufructo de las riquezas y la propiedad de las tierras de sus vasallos." (CÓRDOVA, 1973, 222 y ss).

La tesis del dominio originario de la nación incorporada en el párrafo primero del artículo 27, estipulaba que los derechos de la nación están antes que los derechos de los individuos. No poca cosa es esta pues en la afirmación se consigna el abandono de la tesis de los derechos humanos previos a los derechos contenidos en la constitución, el fin de la tesis liberal del iusnaturalismo y la aceptación de la tesis del positivismo en la nueva constitución: la de 1857 había afirmado que ella "reconocía" los derechos de los mexicanos en su artículo $1^{\circ}$; la de 1917, en cambio, establece que ella "otorga" los derechos a los mexicanos.

En el trasfondo de las disposiciones constitucionales reguladoras del trabajo y de la propiedad puede verse una clara inspiración política. Lo es la defensa de los derechos de los desprotegidos bajo el argumento de que se trata de una postura reivindicatoria de los integrantes del bando triunfante en la gesta revolucionaria. Pero también lo es la regulación de la propiedad que persigue el objetivo de ejercer, desde las instituciones del Estado, el control del derecho de propiedad. Y lo es la postura asumida por nuestros padres fundadores ante el carácter o "naturaleza" de los derechos humanos, los que son creados y otorgados por la Constitución, no son previos a ésta y le corresponde a la Constitución sólo su reconocimiento. El constitucionalismo que mira el rostro político de la constitución ve aquí un ejercicio de ordenación del poder, de reconstitución de un sistema de dominación con apoyo en la creación de condiciones diversas para ejercer el dominio y no sólo una sustitución de élites. 
Pero no cabe duda que se aprecia igualmente un constitucionalismo jurídico que pone el acento en la normatividad resultante de la incorporación de disposiciones constitucionales reguladoras de las condiciones laborales y de las condiciones del derecho de propiedad. Es decir, la observación hecha sobre la necesidad de incorporar instrumentos jurídicos protectores de los desvalidos, desde la constitución, deja apreciar un normativismo constitucional soportado en el reconocimiento del mayor peso de reglas que fijan al legislador secundario no únicamente una competencia para regular las relaciones laborales, sino muchos de los contenidos con los cuales ese legislador habría de desarrollar los instrumentos protectores de las condiciones de trabajo y de vida de los trabajadores. De igual manera, la incorporación de la tesis de la propiedad originaria de la nación adquirió en la Constitución la categoría de disposición fundamental, un principio constitucional que animó muchas reglas jurídicas que desarrollaron diversas formas de ejercer la propiedad, y dio sustento a los correspondientes actos jurídicos que la constituían. No solamente la regulación de la propiedad agraria, en sus variantes de propiedad individual, ejidal y comunal sino también la del régimen de explotación de los minerales, y "los jugos" de la tierra -expresión de Pastor Rouaix-, como el petróleo.

Es probable que las dos condiciones mencionadas del constitucionalismo mexicano, esto es, en primer lugar su característica de impregnar de contenido social a sus disposiciones, agregando, con audacia, disposiciones inéditas entre las constituciones, según la teoría sostenía, y, en segundo lugar, la diversa de construir las bases de un aparato de poder formidable que perduró durante muchas décadas, se hayan grabado en la memoria y en las vivencias de los mexicanos de manera más viva que las demás y también conformen los elementos definitorios de nuestro constitucionalismo que con mayor insistencia señalen sus estudiosos. ${ }^{8}$

De esta manera, el constitucionalismo mexicano fue, durante muchas décadas, uno que promovió, que reguló una determinada forma de vida. Pero icuál era esa forma de vida apoyada en la Constitución de 1917, cómo se vivió el constitucionalismo a partir de la emisión del documento constitucional en febrero de 1917? Una incipiente propuesta de respuesta puede ser intentada en este limitado espacio. En el siguiente apartado apuntaremos algunas consideraciones sobre la vivencia del constitucionalismo mexicano desde 1917.

\section{LAS EDADES DEL CONSTITUCIONALISMO MEXICANO DE 1917}

En este apartado vamos a abordar una interpretación del proceso evolutivo de la Constitución de 1917 que considera solamente los cambios de mayor calado en nuestro constitucionalismo. Las modificaciones que, según nuestro punto de vista, han marcado la historia constitucional mexicana permiten segmentarla en dos grandes etapas o edades. La primera la hemos denominado de constitucionalismo sometido y la otra como edad del constitucionalismo balanceado. De acuerdo con este criterio, en nuestra opinión, la primera etapa se significa por marcar el énfasis en lo político sobre lo jurídico. La segunda, así lo entendemos, ha hecho girar el centro de atención constitucional y ha logrado imprimirle 
un sello complejo que evidencia un diálogo entre el carácter político predominante con anterioridad y el carácter jurídico que ha asumido plenamente nuestro constitucionalismo. Comenzamos invocando posturas teóricas que nos provean de utilidad en el estudio de un constitucionalismo que está en desarrollo. En la sección subsecuente formularemos algunos comentarios sobre reformas constitucionales concretas de significación mayor, aunque en la selección de las reformas exista alguna dosis de inevitable subjetivismo.

De acuerdo con el jurista alemán Konrad Hesse, ${ }^{9}$ la cualidad de una constitución, esto es, lo que cualifica a un texto normativo como constitución, en el sentido actual del término constitución, es la función que cumple al posibilitar y garantizar un proceso político libre, racionalizando y limitando el ejercicio del poder, para asegurar la libertad individual.

En línea con la identificación del constitucionalismo actual, citamos al profesor madrileño Pedro de Vega quien sostiene que:

El Estado constitucional cimenta su estructura en dos pilares fundamentales: por un lado, en el principio político democrático; por otro, en el principio jurídico de la supremacía constitucional. Conforme al principio político democrático se entiende que corresponde al pueblo, en cuanto titular de la soberanía, el ejercicio indiscutible del poder constituyente. Según el principio de supremacía, se considera que la Constitución es lex superior, que obliga por igual a gobernantes y gobernados (DE VEGA GARCÍA, 2006, p. 1).

Las expresiones transcritas que confrontan norma y política como las condiciones más propias del constitucionalismo nos ofrecen la ocasión para recuperar la fértil distinción entre constitución y constitucionalismo, entre texto y vivencia o experiencia. Es verdad que, en general, esto es, en las experiencias de países diversos, la riqueza del segundo término supera la del primero como elemento explicativo de la constitución. Sin embargo, es necesario voltear la mirada hacia la experiencia mexicana para aquilatar las condiciones del ejercicio de nuestro constitucionalismo.

Nuevamente citando a Hesse, esta vez de la mano de Manuel Aragón, se afirma que una de las características del constitucionalismo actual es su "capacidad evolutiva", y ésta se expresa ya a través de las reformas y adiciones incorporadas de manera formal, es decir, las que cumple el órgano competente para reformar la constitución, pero sobre todo por medio del ejercicio de la interpretación constitucional desplegada por los tribunales constitucionales (ARAGÓN REYES, 1998, p. 29). Sin duda las percepciones de un órgano político como lo es el que tiene la competencia para modificar el texto constitucional y el órgano jurisdiccional que interpreta las disposiciones constitucionales son -o pueden serlo- diversas. En consecuencia, subestimar el actuar de cualquiera de estos órganos puede convertirse en un ejercicio científicamente distorsionante. Por ello, resulta necesario aquí llamar la atención sobre el intenso y creciente actuar del órgano competente para incorporar reformas al texto de la constitución mexicana. En nuestra vivencia jurídica, la adaptabilidad de la constitución mediante el ejercicio de la facultad de incorporar reformas expresas al texto escrito, ha sido una función de la constitución que el constitucionalismo mexicano 
ha ejercido intensamente. Los números son elocuentes, en tanto que podemos encontrar el registro de 701 reformas al texto constitucional en este centenario. ${ }^{10}$

Al mismo tiempo, se anticipa que el giro desde el constitucionalismo que llamamos sometido hacia el bautizado como balanceado está asociado con el reforzamiento de la vía jurisdiccional del ejercicio adaptativo de la constitución mexicana. Esta vía ciertamente también ha estado presente desde 1917 y hunde sus raíces en etapas anteriores. El amparo mexicano subsiste desde 1847, y las controversias constitucionales se encontraban contempladas desde el texto de 1917. Sin embargo, durante numerosas décadas la regulación sobre la justicia constitucional así como la actitud institucional y el carácter admitido para la justicia constitucional mexicana no le conferían a los tribunales que la impartían el papel de principal intérprete de la norma constitucional en el proceso de adaptación entre norma y realidad. El protagonista de este proceso adaptativo lo fue, por muchas décadas, el órgano reformador constitucional. Esta circunstancia nos permitió señalar, en un ejercicio analítico con perspectiva historicista, que desde 1917 y hasta 1994 el constitucionalismo mexicano bien puede ser llamado constitucionalismo sometido, pues se encontraba condicionado a los intereses y sometido a la lógica de acción de los órganos políticos, especialmente el competente para reformar la constitución. ${ }^{11}$

En esa misma línea analítica, hemos defendido la propuesta de nombrar el periodo posterior a 1994 de la historia constitucional mexicana como la edad del constitucionalismo balanceado, en tanto que se ha superado el casi monólogo del órgano político que reforma la constitución para dar paso a una nueva etapa de nuestra historia constitucional como consecuencia de dos importantes reformas constitucionales, una en 1994 y otra en 2011, mediante las cuales los tribunales constitucionales participan ahora muy activamente del carácter evolutivo de la constitución, mediante su ejercicio interpretativo, creándose, así, un juego interpretativo entre estos dos órganos constitucionales, el texto constitucional y la sociedad mexicana. ${ }^{12}$

Se comprende la importancia de las reformas invocadas en el párrafo anterior si recordamos, en primer lugar que, en la primera, publicada el 31 de diciembre de 1994, la Constitución mexicana sufrió el cambio más importante en el ámbito de la justicia constitucional, en dos vertientes. En la primera vertiente, que tocó los aspectos orgánicos, pueden recordarse, entre otros aspectos de importancia, la reducción de 26 a 11 miembros integrantes de la Suprema Corte de Justicia, por una parte, y, en segundo lugar, con la intención de liberar de las cargas laborales de tipo administrativo al órgano Pleno de la Suprema Corte de Justicia, se creó un órgano novedoso responsable del control de todos los órganos judiciales que integran al Poder Judicial de la Federación, con excepción solamente de la propia Suprema Corte de Justicia, denominado Consejo de la Judicatura Federal.

La segunda vertiente de la reforma de 1994 impactó profundamente las cuestiones procedimentales de la justicia constitucional. Hasta esa fecha podía considerarse que, de hecho, el juicio de amparo constituía la única vía eficaz de control de la regularidad constitucional 
de los actos del poder público, limitada a los actos que afectaran los derechos fundamentales de los particulares. En la reforma invocada, el constituyente fortaleció considerablemente las facultades de control de la regularidad constitucional de la Suprema Corte de Justicia también en dos vertientes. Por un lado, al otorgarle una facultad nueva que denominó acción de inconstitucionalidad, consistente en el poder jurídico para determinar la inconstitucionalidad de disposiciones violatorias de la Constitución, únicamente ante la pura emisión de la norma, esto es, sin exigir un acto de aplicación o una posible conculcación concreta de un derecho de los gobernados, como ocurre en el juicio de amparo. La otra facultad de control constitucional reforzada en ese año fue la vía conocida como controversia constitucional la cual, si bien existía desde 1917, adolecía en la práctica de una eficacia casi nula. Esta vertiente de ejercicio del control de constitucionalidad abrió la puerta para que la Suprema Corte de Justicia cumpliera un papel protagónico de árbitro de los conflictos competenciales entre órganos cuando estos conflictos tienen su origen en cuestiones constitucionales.

El impacto de la reforma constitucional de 2011 a que nos referimos fue diverso y quizá con un sentido más profundo que la de 1994. Es verdad que podemos defender la tesis que nos encontramos en la misma edad del constitucionalismo balanceado porque los contenidos incorporados en 2011 avanzan en la misma línea del fortalecimiento del control jurisdiccional de la constitución. Sin embargo, las disposiciones nuevas han reorientado o incorporado un diverso sustento filosófico a nuestra Carta Magna. Vale apuntar asimismo que mientras la reforma de 1994 centró sus contenidos en los aspectos orgánicos y procesales de la justicia constitucional, la de 2011 enfocó la mira en cuestiones materiales e instrumentales.

Como hemos afirmado, la reforma constitucional, publicada el 10 de junio de 2011 incorpora a la Constitución una concepción moderna de los derechos humanos. El centro de las enmiendas a 11 artículos constitucionales fue la contundente determinación de que los derechos humanos son la materia propia de la Constitución; que estos derechos humanos se encuentran contenidos en el propio texto y también en los tratados internacionales signados por México; que las garantías individuales han asumido un concepto constitucionalmente más adecuado, limitándose a los derechos procesales constitucionales; y finalmente el reconocimiento jurídico pleno de la juridicidad de los tratados internacionales que contienen derechos humanos. ${ }^{13}$ Así, podemos afirmar que el artículo 133 constitucional tiene ahora un contenido diverso cuando afirma que los tratados internacionales "son ley suprema de toda la Unión”. ${ }^{14}$

Por último, denominamos aspectos instrumentales a los que atienden a la manera de desarrollar los contenidos de las disposiciones en materia de derechos humanos. A estas cuestiones se refieren los nuevos párrafos segundo y tercero del artículo $1^{\circ}$ de la Constitución. De los contenidos del párrafo segundo del artículo $1^{\circ}$ podemos inferir que incorpora un "instrumento" muy poderoso para lograr la protección de los derechos humanos al prescribir el uso de la pauta o directriz interpretativa denominada criterio de la "interpretación conforme" en materia de derechos humanos, cuando sostiene que "(l)as normas relativas 
a los derechos humanos se interpretarán de conformidad con esta Constitución y con los tratados internacionales de la materia [...]". (CONSTITUCIÓN POLÍTICA DE LOS ESTADOS UNIDOS MEXICANOS, 1917, p. 2). La directriz interpretativa se completa con otro elemento instrumental que la doctrina denomina el principio "pro personae", consistente en la disposición que obliga a actuar con una actitud que favorezca la protección de los derechos humanos de las personas.

Similar es el carácter instrumental del párrafo tercero del mismo artículo $1^{\circ}$ cuando establece que:

Todas las autoridades, en el ámbito de sus competencias, tienen la obligación de promover, respetar, proteger y garantizar los derechos humanos de conformidad con los principios de universalidad, interdependencia, indivisibilidad y progresividad. En consecuencia, el Estado deberá prevenir, investigar, sancionar y reparar las violaciones a los derechos humanos, en los términos que establezca la ley (CONSTITUCIÓN POLÍTICA DE LOS ESTADOS UNIDOS MEXICANOS, 1917, p. 2).

Los contenidos de estas disposiciones se convierten en instrumentos para la protección de los derechos humanos de las personas, en tanto que fijan varios extremos muy importantes: los sujetos obligados, que son, sin excepción, todas las autoridades del país; las acciones a cumplir de manera vinculante por dichos sujetos, expresadas en las cuatro contenidos en los verbos "promover, respetar, proteger y garantizar"; el objeto de las acciones, precisamente los derechos humanos; $y$, finalmente, los criterios que dan soporte a las mencionadas acciones contenidos en los principios constitucionales de "universalidad, interdependencia, indivisibilidad y progresividad". El conjunto de contenidos de esta disposición construye un marco instrumental mediante el cual los derechos humanos, que se han convertido en el centro o corazón de la Constitución, han de ser protegidos mediante la aplicación de estas disposiciones. La disposición final de este párrafo, por una parte, fija obligaciones para "el Estado" contenidas en otras cuatro acciones a cumplirse por dicho sujeto: prevenir, investigar, sancionar y reparar las violaciones a los derechos humanos, y, por otra, vincula al legislador ordinario a emitir una ley que regule la manera en que esas obligaciones habrán de cumplirse.

\section{LA MIRADA POLÍTICA. LAS REFORMAS DE MAYOR IMPORTANCIA POR PERIODOS POLÍTICOS DEL CONSTITUCIONALISMO MEXICANO}

El apartado anterior puso el acento en la gran transformación del constitucionalismo mexicano operada a partir de 1994. Como se había sostenido, coexisten ahora de manera muy interesante las visiones política y jurídica de la constitución a través de las acciones de los órganos cúspide del sistema mexicano, la corte constitucional y el órgano revisor constitucional. En este apartado vamos a prestar atención e la mirada política del constitucionalismo, esto es, atender el comportamiento del órgano político responsable de interpretar y actualizar de manera expresa y formal los contenidos de la constitución. 
En consecuencia, pondremos el acento en algunas reformas constitucionales puntuales que son sin duda de gran calado en la historia de nuestro constitucionalismo. Como hemos anticipado, esta selección puede adolecer de subjetividad, considerando el elevado número de modificaciones formales a la Constitución en este siglo de existencia. Para efectos de dimensionar la magnitud de la actividad como intérprete jurídico fundamental del constitucionalismo mexicano que hemos podido asignar al órgano competente para reformar la Constitución, nos parece útil, en primer lugar, presentar el número de reformas constitucionales incorporadas al texto constitucional de 1917 al 5 de febrero de 2017, esto es, en el siglo de su existencia, en la siguiente gráfica. La información la hemos segmentado por periodo presidencial para efectos de medir la intensidad creciente del ejercicio de esta función. El número de reformas sigue el criterio de una reforma por artículo/decreto de reforma, por ejemplo, si un decreto contiene 2 artículos reformados, entonces se cuenta como 2 reformas, o si en un mismo día se llegaren a publicar en el Diario Oficial dos diversos decretos de reforma constitucional y en el primero de ellos se reforman 2 artículos y en el segundo 3 , se cuentan 5 reformas constitucionales. El gráfico muestra que al cumplirse el siglo de vida de nuestra Constitución, se han reformado 701 artículos, a través de la expedición de 230 decretos de reforma constitucional, hasta el 5 de febrero de $2017 .{ }^{15}$

\section{Gráfica 1 - 701 Artículos Reformados en cien años de la Constitución Mexi- cana (5 de Febrero de 1917-5 de Febrero de 2017) por Periodo Presidencial}

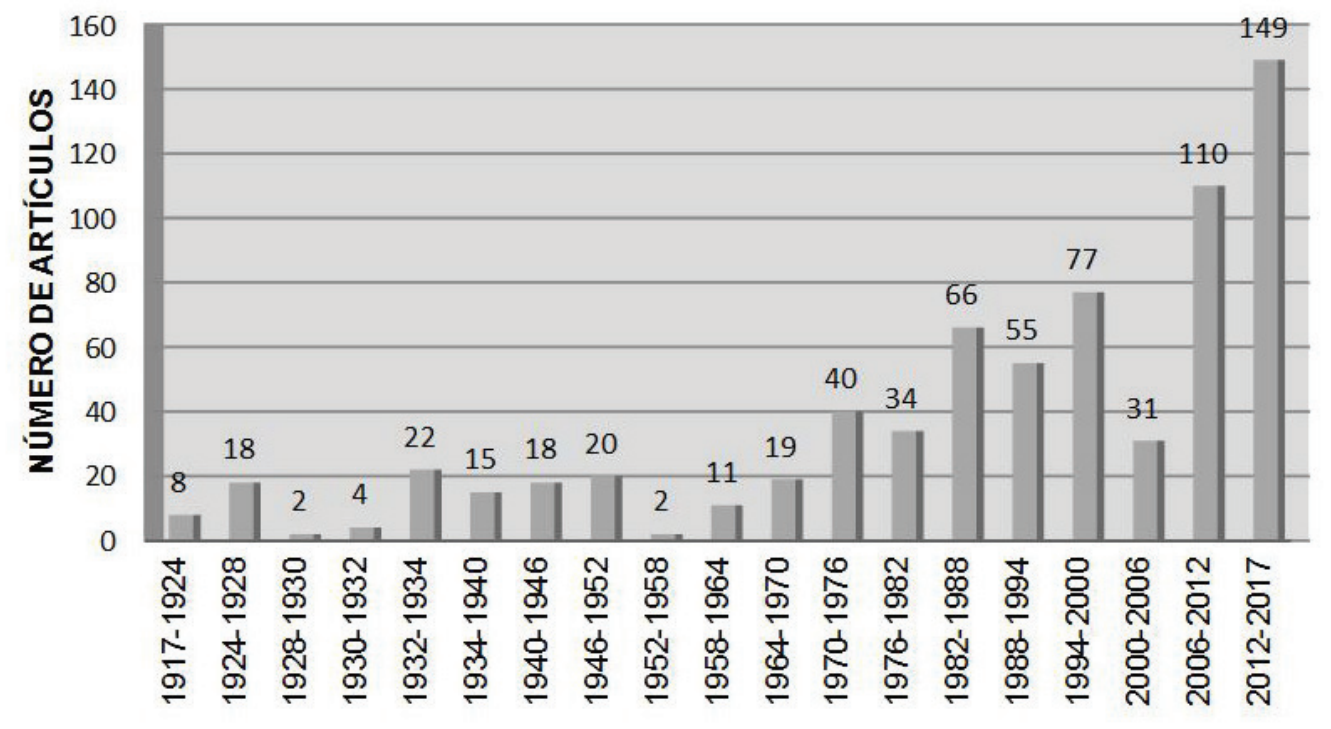

Fuente: Cuadro elaborado por el autor, con apoyo de Alan Yavé Cortés Juárez, con información de la página de la Cámara de Diputados, Ciudad de México (2017a, 2017b).

En el apartado anterior ofrecimos una segmentación de la historia del constitucionalismo mexicano en dos grandes etapas o edades. En esta sección vamos a seleccionar algunas reformas puntuales a la Constitución que nos permitan ubicar momentos en los cuales el 
intérprete político del constitucionalismo mexicano ha modificado el principal ordenamiento jurídico del sistema mexicano. Recordamos que los actos formales de reforma constitucional son decretos de reforma, y que la historia del centenario constitucional acumula 230 decretos con este valor jurídico, en este periodo.

Consideramos que la Constitución es modificada de manera formal cuando el órgano que tiene esa facultad ha actuado al entender que se ha presentado la necesidad de modificarla por razones sociales o políticas o económicas o incluso teóricas, esto es, puede haber una diversidad de causas por las cuales se modifica una constitución. Si esto es verdad, entonces puede inferirse que cada uno de los 230 decretos modificatorios mencionados fue la reacción del reformador constitucional a causas como las mencionadas. Con la intención de comprender el sentido de los decretos reformatorios que aquí vamos a mencionar, nos parece adecuado ubicarlos en el contexto político en el cual fueron emitidos. Para ello, proponemos una agrupación de decretos que atienda estos contextos políticos, sin pretender, con ello, una revisión o alteración a los dos grandes segmentos del constitucionalismo mexicano admitidos en el apartado anterior. De hecho, esta segmentación que obedece a criterios políticos no coincide con la caracterización de las edades del constitucionalismo mexicano.

El constitucionalismo mexicano, analizado conforme a criterios políticos principalmente, transitó primero por un proceso de consolidación, durante las primeras dos décadas de su existencia. Siguió después un largo periodo caracterizado por un sistema político de presidencialismo fuerte que se soportaba en un régimen de partido hegemónico. Finalmente, este segundo periodo fue sustituido por otro que se significa por un ingreso a un sistema democrático, que le llamamos en construcción, en el cual nos encontramos en la actualidad.

\section{LA CONSOLIDACIÓN DEL CONSTITUCIONALISMO MEXICANO}

Sería ingenuo admitir que el constitucionalismo mexicano nace consolidado en 1917, esto es, que la sola expedición del texto condujo a la gestación de una nueva realidad política y jurídica. Al contrario, los hechos de las primeras dos décadas evidencian importantes titubeos en la consolidación del naciente orden, lo que nos hace pensar en la dificultad para generar un consenso, a partir de un proceso revolucionario, sobre una cultura jurídica transformada a partir de una nueva constitución. En el transcurso del primer decenio, dos presidentes fueron asesinados, Venustiano Carranza en mayo de 1920, a meses de concluir su periodo presidencial, y el presidente electo Álvaro Obregón, en julio de 1928, antes de asumir formalmente el poder. También registramos un retroceso lamentable que hizo caer el principio político básico de la no reelección -y que había causado millones de muertos en la gesta revolucionaria-, a través de una reforma constitucional que volvía a admitir la reelección mediata para el cargo de la presidencia de la República, hecha prácticamente a medida para que el expresidente Obregón pudiera de nuevo ocupar este cargo. La crónica histórica registra además el denominado "Maximato", término que denota el periodo en el cual el ex presidente Plutarco Elías Calles, que había ocupado este cargo entre 1924 y 1928, a la 
muerte de Obregón logró controlar el poder ejecutivo de facto. Y, en medio, una guerra civil más, llamada "Guerra de los cristeros", en la cual en diversas zonas del país, particularmente en el centro de éste, se enfrentaron importantes sectores de la población contra las fuerzas gubernamentales, por razones asociadas a la libertad de culto, particularmente el católico. ${ }^{16}$ El triunfo político de Lázaro Cárdenas, ya presidente en funciones, sobre Plutarco Elías Calles, que se dio en 1935, marca la consolidación del sistema político mexicano, soportado en un presidencialismo muy fuerte y un sistema de partido dominante, que perduró durante muchas décadas, hasta $1977 .{ }^{17}$

Entre los sucesos narrados, sólo el acto de reelección presidencial fue conforme a derecho. En este caso se modificó el artículo 33 constitucional para incorporar una regla que permitiera la reelección mediata, mediante una reforma publicada el 22 de enero de 1927 en el Diario Oficial de la Federación; sin embargo, esta norma fue nuevamente modificada, entre otras disposiciones, para prohibir de manera total y definitiva la reelección presidencial, por diversa reforma publicada el 29 de abril de 1933. Asociada al campo de regulación del titular del Poder Ejecutivo Federal otra importante reforma de esta primera etapa de consolidación del constitucionalismo mexicano fue la ampliación del periodo presidencial de 4 a 6 años, mediante una reforma publicada el 24 de enero de 1928.

Cabe concluir que entre la fecha de expedición de la Constitución mexicana y la conclusión del periodo de formación o consolidación del sistema político mexicano al arribar Cárdenas a la presidencia, se expidieron los primeros 19 decretos de reforma constitucional. Las reformas de mayor importancia son, en nuestra opinión, las ya mencionadas a las que cabría agregar la reforma que estableció el carácter socialista de la educación, impulsada por Calles, publicada el 13 de diciembre de 1934, disposición controversial que fue suprimida por decreto de 30 de diciembre de 1946.

\section{LA EXPERIENCIA DE UN PRESIDENCIALISMO SOBRESALIENTE CON PARTIDO HEGEMÓNICO}

Este periodo dio inicio entre 1934-35 al entenderse consolidado el sistema político y duró hasta 1977, año en el cual el régimen se vio obligado a incorporar reglas de apertura política a los grupos sociales y colectivos opositores al sistema de control que había estado funcionando razonablemente durante estos años. En estas cuatro décadas de "partido hegemónico" vieron la luz 66 decretos de reforma constitucional, del número 20 al 85 . Haremos referencia a algunas cuestiones que nos parece de especial interés en el desarrollo del constitucionalismo mexicano de esas épocas, a partir de las reformas incorporadas al texto constitucional. ${ }^{18}$

Mencionamos la materia política en primer lugar pues nos permite poner en perspectiva las reformas constitucionales del periodo. El sistema creado constitucionalmente permitía el juego democrático de manera formal, en tanto que los ciudadanos podían votar y ser elegidos para cargos de elección popular conforme a derecho. Sin embargo, como bien lo ha estudiado 
José Ramón Cossío desde la perspectiva jurídica, ${ }^{19}$ las reglas constitucionales aplicables razonablemente establecían la elección de los titulares de los órganos ejecutivo y legislativo y los integrantes de estos órganos poseían el control de la producción de normas jurídicas. Esto es natural en cualquier democracia constitucional. Pero estas reglas se completaban con otros mecanismos jurídicos mediante los cuales se ejercían otros controles sobre las voluntades de ciudadanos, especialmente los trabajadores y los campesinos, los cuales eran consistentemente avalados por los tribunales.

Sobre los integrantes de la clase laboral el control se ejercía mediante las denominadas "cláusula de admisión" y "cláusula de exclusión" que consistían, resumidamente, en la posibilidad de otorgar contratos de trabajo solamente a los integrantes de sindicatos y, de manera concomitante, el derecho de estas organizaciones de trabajadores de solicitar a los patrones la conclusión de la relación laboral a los trabajadores que no pertenecieran a alguna organización sindical. En el fondo, la operación de estas reglas podía entenderse como un control real sobre las posibilidades de subsistencia de muchos mexicanos y el consecuente control de las voluntades políticas de ellos por la vía de los líderes sindicales, por este medio. Paralelamente, se obligaba a las organizaciones sindicales a estar integradas en las centrales sindicales, de manera que las estructuras de sindicatos ejercían controles sobre sus miembros. Reglas parecidas operaban para los trabajadores burocráticos federales. El sistema se cerraba con la inclusión de las organizaciones sindicales en el denominado "sector obrero" que formaba parte del partido político dominante, especialmente a partir de la creación del Partido del Revolución Mexicana, cuya constitución fue impulsada por el presidente Lázaro Cárdenas en 1938, y que venía a sustituir al Partido Nacional Revolucionario, creado a instancias del Presidente Calles en 1928 y, finalmente el sustituto del anterior, el Partido Revolucionario Institucional, creado por instancias del presidente Miguel Alemán, en 1946.

Por el lado de los trabajadores del campo, las condiciones de control sobre ellos se ejercían a través de la esperanza de otorgamiento de tierras en los actos de reparto que los diferentes presidentes realizaban, por una parte. En el control sobre el acceso al capital para poder hacer trabajar la tierra, que fue ejercido por instituciones bancarias públicas, como el Banco Nacional de Crédito Ejidal (Banjidal), que otorgaba préstamos "a fondo perdido" a los trabajadores del campo. Y, finalmente en los controles de tipo burocrático que las autoridades de las dependencias federales ejercían sobre las autoridades ejidales y comunales, primero el Departamento de Asuntos Agrarios y Colonización y luego la Secretaría de la Reforma Agraria. En resumen, el dominio sobre las voluntades políticas de los campesinos se ejercía a través de la administración de la pobreza, como sostiene el autor citado. También aquí el sistema de control incluía la obligada inmersión de las organizaciones de campesinos en otro sector del partido dominante, el "sector campesino".

Además del control del ejercicio del voto activo a través de los mecanismos mencionados, el sistema operaba con las instancias gubernamentales encargadas de desarrollar el ejercicio de las elecciones y su calificación. Los mecanismos de integración de todas las instancias, desde su cúspide 
hasta las municipales permitían que los integrantes del partido político dominante condujeran el sentido de las decisiones de estos órganos administrativos. A esto se sumaba la inexistencia práctica de mecanismos jurídicos para impugnar jurisdiccionalmente decisiones tomadas por los órganos administradores de las elecciones. El conjunto de disposiciones reguladoras de las elecciones en estos años de hegemonía de un partido político conduce a Cossío a sostener que la legitimidad de este régimen no fue democrática sino una de tipo corporativista.

En este contexto, las reformas constitucionales de este periodo que impactaron la materia político-electoral no afectaron en el funcionamiento del sistema de control corporativista creado desde el poder. En cuanto a la materia electoral el otorgamiento del voto a la mujer se incorporó por la reforma publicada el 12 de febrero de 1947, aunque de manera limitada porque lo restringió al espacio de las elecciones municipales. El derecho para participar en las elecciones nacionales de manera plena se otorgó a la mujer por decreto de 17 de octubre de 1953 con lo cual dio inicio un largo proceso de igualación de los derechos político-electorales fundamentales en México, con derivaciones ya entrado el siglo XXI. Conviene recordar que la firma por México del pacto creador de la Organización de las Naciones Unidas ya le había generado a nuestro país, desde 1945, la obligación de considerar la igualdad jurídica entre el hombre y la mujer, y que el otorgamiento del voto le representaba a nuestro país un compromiso internacional.

También deben mencionarse las reformas al artículo 73 constitucional, por su significado en el federalismo mexicano y que son, por cierto, una constante en nuestro constitucionalismo. Las modificaciones a este dispositivo tienen el efecto de centralizar la facultad legislativa en los órganos federales aplicando la regla del artículo 124 que cierra el sistema de distribución de competencias entre la Federación y los estados al fijar que las atribuciones no concedidas de manera expresa por la Constitución a la Federación se entienden que están reservadas para su ejercicio por los Estados. Esta centralización ha conllevado un paralelo acrecentamiento del poder del presidente, en tanto que éste operaba como institución central del sistema político.

En un sentido de reformas con el mismo tono político, recordamos decretos modificatorios constitucionales que implicaban un reforzamiento del control por el presidente de la República sobre otros órganos. Llaman la atención otras dos diversas disposiciones que fueron incorporadas al texto constitucional en este periodo. En el primer caso el presidente Cárdenas logró la incorporación de una regla que le permitió renovar a los miembros de la Suprema Corte de Justicia, mediante la expedición de un decreto reformatorio al artículo 94, de 15 de diciembre de 1934, que estableció una duración de 6 años a los ministros de la SCJN, suprimiendo la denominada "investidura vitalicia" de los ministros de la SCJN, y adicionalmente aumentó el número de ministros a 21 y creó una cuarta sala. Como lo decía la iniciativa que el propio Cárdenas, en calidad de presidente electo presentó a su partido, y luego se sometió al órgano reformador constitucional, la renovación de la Suprema Corte se entendía en ese momento como un imperativo porque México era "(u)n país joven, que está propugnando por establecer un nuevo concepto de justicia distributiva [...].” (CABRERA ACEVEDO, 1999, p. 26). 
Una línea muy interesante de las relaciones entre el poder político y el poder de los jueces se reconoce en un singular decreto de 12 de agosto de 1938 mediante el cual se reformó el artículo 49 constitucional. Con este acto legislativo de reforma constitucional se trataba de recuperar el sentido correcto de lo que en ese momento podía entenderse como la única excepción a la regla básica que dicho artículo contiene cuando establece la prohibición de suspender el ejercicio de la división de poderes, y la excepción se encontraba acotada a los casos de lo que se denominaba suspensión de las garantías constitucionales, en cuyo caso el titular del Poder Ejecutivo Federal podía ser autorizado por el Congreso de la Unión para legislar de manera directa. Ahora bien, en varias ocasiones el Congreso de la Unión había otorgado al titular del Ejecutivo federal facultades extraordinarias para legislar que no eran realmente consecuencia de la suspensión de garantías. Y los tribunales constitucionales, ante la interposición de demandas de amparo por vicios de constitucionalidad en los casos de aplicación de leyes emitidas en ejercicio de dichas facultades extraordinarias, habían estado rechazando el amparo de manera consistente al interpretar que la prohibición del 49 constitucional se refería solamente al otorgamiento general de facultades para legislar pero no a los casos individuales. Es más, esta interpretación era consistente con la que la Suprema Corte había fijado durante la vigencia de la Constitución de 1857, ante casos análogos. Pero el sentido correcto de este artículo, en opinión del Presidente Cárdenas y del órgano reformador constitucional, era el limitado al caso de la suspensión de garantías. Consecuentemente, mediante la reforma al artículo 49 se repitió la prohibición pero, entiéndase bien, no por error de técnica legislativa sino para corregir las interpretaciones erróneas de los órganos jurisdiccionales. Debe recordarse que la doctrina extranjera, particularmente la norteamericana, admite como una de las funciones que cumple la reforma constitucional precisamente la de corregir las eventuales interpretaciones equivocadas de los tribunales constitucionales. En la reforma en materia electoral de 13 de noviembre de 2007 se repetirá un ejercicio corrector, mediante el cual se fijaría un criterio para resolver un asunto interpretativo que había enfrentado a la Suprema Corte de Justicia y a la Sala Superior del Tribunal Electoral del Poder Judicial de la Federación. ${ }^{20}$

Es importante recordar también algunas reformas constitucionales que inciden en el contexto de la regulación del régimen de propiedad de bienes por parte del Estado. En cuatro diferentes decretos el órgano reformador fijó reglas constitucionales fundamentales para ejercer el control del aprovechamiento de los bienes que le permitieron al Estado administrar recursos energéticos en un sentido propiamente monopólico, hasta años muy recientes. Nos referimos primero al decreto de 9 de noviembre de 1940, que prohibió la concesión a particulares en materia de petróleo. No requiere recordarse la enorme trascendencia en el desarrollo mexicano de esta acción política que formó parte de la espinosa cuestión de la expropiación petrolera, en la cual el presidente Cárdenas salió airoso. También al decreto de 29 de diciembre de 1960, al establecer el monopolio del Estado en materia de conducción, transformación, distribución y abastecimiento de energía eléctrica, prohibiendo 
expresamente la posibilidad de otorgar concesiones a particulares. La tercera reforma en esta línea fue el decreto de 6 de febrero de 1975 por el cual se otorgó a la Nación el dominio sobre el aprovechamiento de los combustibles nucleares. Finalmente la reforma publicada el 6 de febrero de 1976, que estableció la creación de la zona económica exclusiva más allá del mar territorial.

En materia de derechos, mencionamos dos decretos reformatorios que nos parecen muy importantes, entre muchos otros más, de esta etapa de presidencialismo con partido hegemónico. El primero de ellos, de 5 de diciembre de 1960, que incorporó el apartado B al artículo 123 constitucional para establecer las reglas básicas en materia de regulación del trabajo burocrático federal y el de los territorios. Y el decreto de 31 de diciembre de 1974, que estableció, finalmente, la igualdad constitucional del hombre y de la mujer, materia en la cual estamos comprometidos a convertirla en realidad social y cultural y no sólo formal.

El sistema comienza a declinar alrededor de los años setentas. Factores económicos no privativos de México, como fue el caso del fin del ciclo económico de la posguerra, impulsaron un declive de los beneficios sociales que el sistema había podido aportar. Dentro del país, la masacre de Tlatelolco en octubre de 1968, que conmocionó a la sociedad mexicana por la muerte de cientos de estudiantes en manos de miembros del ejército se convirtió en un poderoso detonante social que al paso de pocos años empujaría al régimen a incorporar reformas políticas importantes con sustento en modificaciones a la Carta Fundamental. En este contexto, se emitieron algunas reformas de carácter electoral. Es el caso del decreto de 22 de diciembre de 1969, que redujo la edad mínima para ser considerado ciudadano y poder ejercer el derecho al voto activo a los 18 años. En cuanto hace al derecho a ser votado, por reforma publicada el 22 de junio de 1963, se incorporó una interesante figura, propia de los sistemas electorales de representación proporcional, mediante la creación de los diputados de partido. La reforma permitía la asignación de diputados a los institutos políticos que hubieran obtenido al menos un porcentaje de 2 por ciento de la votación. La regla señalaba el límite de 20 diputados por partido político en esta modalidad. Más tarde, el porcentaje requerido para obtener curules se redujo a 1.5 por ciento por decreto de 14 de febrero de 1972. Este mecanismo de asignación de diputados fue un interesante antecedente -aunque poco eficaz- del sistema electoral de representación proporcional, que en 1977 vendrá a modificar significativamente la forma de integración de los congresos mexicanos. En la misma línea de reformas al derecho al voto pasivo, por reforma publicada el 14 de febrero de 1972, se redujo a 21 años la edad para ser diputado federal y a 30 años la edad para ser senador.

\section{EL PERIODO DEMOCRÁTICO DE LA CONSTITUCIÓN MEXICANA. DE 1977 A LA ACTUALIDAD}

Para abordar el análisis de lo que hemos denominado el periodo democrático del constitucionalismo mexicano nos puede ser de utilidad la representación gráfica de los cambios en la integración en el Congreso de la Unión, en particular en la Cámara de Diputados, con 
los cuales se evidencian las transformaciones desde un sistema de partido dominante hacia un sistema político plural, de contenido democrático. La gráfica contiene el registro de estos cambios desde 1976 hasta la actual composición de esta Cámara, en 2017. Los datos contenidos en la gráfica muestran el impacto de la aplicación de las disposiciones constitucionales en materia política, y, consecuentemente, el contexto político en el cual se desarrollaron las reformas constitucionales del periodo que hemos denominado de la democracia mexicana.

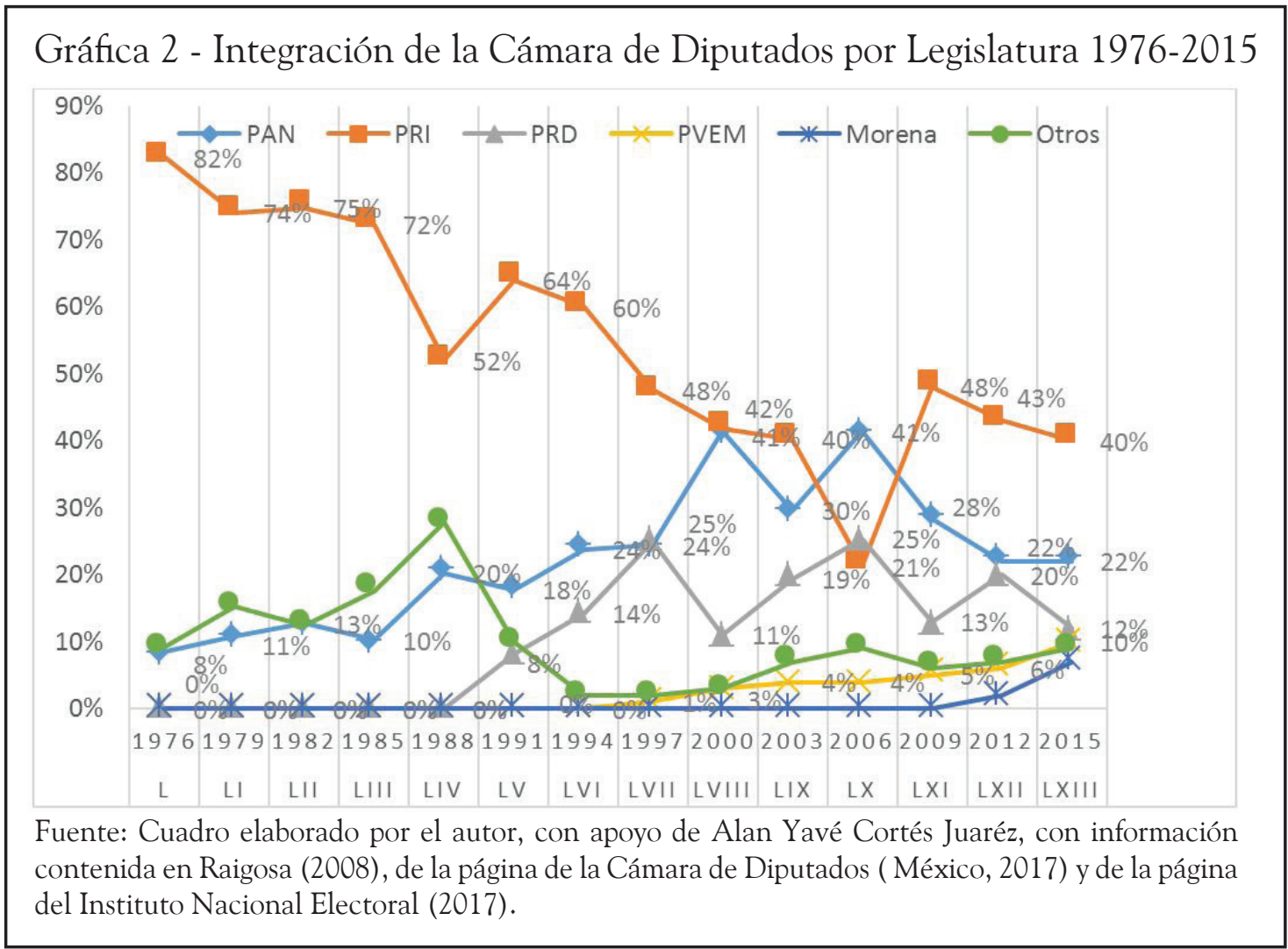

El decreto de reforma constitucional número 86, publicado en el Diario Oficial de la Federación el 6 de diciembre de 1977 constituye el arranque de un proceso definitivo de democratización del sistema, aunque éste ha tenido vaivenes y está “en construcción”. Por esta razón la gráfica se elabora a partir de la legislatura integrada en la etapa inmediata anterior al inicio de vigencia de la reforma de 1977, la Legislatura L, elegida en 1976. La reforma es un parteaguas que pone los cimientos para construir el cambio desde un sistema corporativista hacia un sistema democrático en México, proceso al cual se le ha llamado la reforma política. El proceso de democratización ha venido desarrollándose desde esa fecha hasta la actualidad, a través de decretos de reforma constitucional, los que han sido acompañados de desarrollos legislativos. La última fase importante de la reforma política se dio en 2013.

Los cimientos jurídicos de mayor importancia sobre los cuales se edificó el sistema electoral y el parlamentario, en 1977, son los siguientes:

a) la incorporación del sistema de representación proporcional el cual se sumó al tradicional sistema de mayoría relativa creando un sistema mixto de elección, que es 
el actualmente vigente en nuestro país;

b) la fijación de límites para tener derecho a la asignación de curules conforme al sistema de representación proporcional. Al día de hoy se exige la participación con candidatos por mayoría relativa en al menos doscientos distritos uninominales y el haber obtenido un porcentaje no menor al 3\% de la votación válida emitida para las listas regionales plurinominales;

c) determinación de una composición fija de integrantes de la Cámara de Diputados. Hoy contamos con 500 diputados, 300 elegidos conforme al sistema de mayoría relativa y 200 de acuerdo al sistema de representación proporcional. Antes de la reforma en toda nuestra historia constitucional la relación entre población y escaños se regía por un mecanismo que asociaba un número fijo de población por cada escaño, lo que, naturalmente debía ser modificado conforme el número de la población crecía, pare evitar un crecimiento excesivo de diputados;

d) constitucionalización de los partidos políticos. La reforma constitucionalizó a los partidos políticos, definiéndolos como entidades de interés público. Conforme se fue desarrollando la vida política mexicana, estos institutos políticos se han convertido en los auténticos protagonistas de la política en México, lo que, por cierto, hace recordar la voz partidocracia que la literatura europea usa para nombrar a los regímenes en los cuales son estos institutos políticos los que participan en la política;

e) creación de una nueva fuente de derecho parlamentario que ahora tendrá por eje de regulación una ley federal, basada naturalmente en las disposiciones constitucionales. La creación de esta nueva fuente de derecho parlamentario se circunscribió a las reglas de organización de ambas cámaras federales. Las disposiciones de procedimiento no serán emitidas sino hasta el año 2010, mediante la emisión de sendos reglamentos de procedimiento para cada una de las cámaras del Congreso de la Unión;

f) creación de los órganos parlamentarios denominados grupos parlamentarios. A partir de su creación estos sujetos de derecho parlamentario asumirán el papel protagónico del juego político al interior de los congresos, tanto en ambas cámaras del Congreso de la Unión como en los congresos estatales.

Sucesivas reformas incorporaron instituciones y nuevas modalidades de regulación en materia política las cuales nos han conducido al sistema democrático como hoy lo estamos viviendo. Las de mayor peso son las siguientes:

a) en primer lugar, la reforma de 15 de diciembre de 1986, marca el nacimiento de una justicia electoral profesional, desde un incipiente tribunal administrativo, en ese año, hasta lo que diez años más tarde será un tribunal especializado denominado Tribunal Electoral del Poder Judicial de la Federación, que se ha convertido en la instancia final de calificación jurisdiccional de las elecciones en México. Hemos transitado desde un sistema electoral administrativo hasta uno judicializado pues en nuestra democracia las elecciones son ahora definidas en las salas de los tribunales electorales;

b) más tarde, la reforma de 6 de abril de 1990, señala el inicio de la profesionalización 
del sistema de elecciones mediante la creación de un órgano electoral público autónomo encargado de la organización y desarrollo de las elecciones en México, el hoy denominado Instituto Nacional Electoral, el cual fue consolidándose como el garante de elecciones independientes. En realidad, el control de la organización y desarrollo de las elecciones pasó desde una instancia que logró liberarse de la vigilancia y dominio de instancias gubernamentales hacia otra en la cual se observa una manipulación de los mecanismos de nombramiento de los integrantes del órgano de decisión más importante, el Consejo General del Instituto Nacional Electoral, desde órganos partidistas. También aquí son los partidos políticos los protagonistas;

c) supresión, por reforma de 3 de septiembre de 1993, de la posibilidad constitucional de que un partido político, por sí solo, logre incorporar una reforma a la constitución. La disposición hoy aplicable establece que ningún partido político podría tener por sí mismo, más de 315 diputados, mientras que el número mínimo requerido para lograr reformar la constitución, si es el caso de que la totalidad de diputados estén presentes, es de 334;

d) otra materia importante es la que concierne a la regulación de la materia electoral por instancias federales, que fue incorporada en la Constitución por reforma de 22 de agosto de 1996, en la cual se establecieron las bases para que las entidades federativas emitieran sus legislaciones estatales correspondientes;

e) en 2007, por reforma de 13 de noviembre, con la cual los actores políticos buscaron nuevas fórmulas para mejorar el funcionamiento del sistema electoral, se incorporaron reglas orientadas a reducir el costo de la democracia, prohibiendo la compra de publicidad en radio y televisión, o incorporando reglas diversas para el financiamiento de los partidos políticos. Asimismo, prohibiciones para manejo de recursos públicos en campañas, a fin de respetar la equidad electoral. Sin embargo, lamentablemente el costo de la democracia mexicana es cada vez más elevado y la inequidad electoral continúa presente;

f) entre otras reformas más, no citadas por falta de espacio, resalta la de 10 de febrero de 2014. Es un nuevo esfuerzo para corregir los errores o ineficiencias que resultan de la operación del sistema político. Construye un nuevo esquema de distribución competencial para legislar en materia electoral al instituir la figura de una ley general que regule las elecciones federales y establece las bases para legislar en materia electoral local. Se recupera la reelección para los cargos de elección popular con excepción de presidente de la República y gobernadores de los estados. Se concentran facultades de organización electoral estatal en el nuevo Instituto Nacional Electoral (INE) que sustituye al viejo Instituto Federal Electoral (IFE). También abre la opción para un régimen de gobierno de coalición con lo que el constituyente opta por acercarse a un régimen semiparlamentario ante un eventual escenario de falta de gobernabilidad en sucesivas integraciones de gobierno. Finalmente, instituye la Fiscalía General de la República como organismo autónomo.

Con visión retrospectiva, los legisladores constitucionales de 2007 sostuvieron que la reforma iniciada en 1977 y hasta antes de la reforma de 2007, habían desarrollado la reforma 
política en varios ejes conductores: la creación de un sistema de partidos; la generación de condiciones de competencia equitativa regulando recursos y medios para competir electoralmente; la creación de instituciones electorales autónomas e independientes; la modificación del sistema representativo en el Congreso de la Unión, y la creación de procedimientos confiables y transparentes. ${ }^{21}$

Bien mirados, de estos cinco ejes de la reforma política podría decirse que dos de ellos se han cumplido, y están en el campo del Derecho Parlamentario: un sistema de partidos y un sistema representativo mixto. El resto parece ser más claramente materia electoral en la cual seguimos en construcción pues quizá la equidad electoral, la independencia institucional y los procedimientos son temas en los cuales hemos tenido vaivenes y sinsabores. Con todo y sus defectos, es imposible no concluir que el viejo sistema corporativista, con presidencialismo fuerte y sistema de partido hegemónico desapareció del horizonte del constitucionalismo mexicano. El nuestro es hoy más bien una democracia en desarrollo, con un presidencialismo sin el antiguo dominio del sistema y un sistema plural de partidos.

De varia factura son otras reformas que han perseguido intenciones y propósitos diversos. Mencionamos someramente algunas. Tres de ellas atienden al añejo y espinoso asunto de la religión y la iglesia en el Estado mexicano. En reforma de 28 de enero de 1992 se concede personalidad jurídica a las iglesias y se otorga el derecho al voto activo a los ministros de ellas. Veinte años más tarde, el 30 de noviembre de 2012, el constituyente redefine la forma del Estado mexicano considerándolo una república laica. La tercera reforma, también de reciente data, expedida el 19 de julio de 2013, amplia el ámbito de lo conocido como libertad de creencias. Estas reformas institucionalizan lo que por tantos años se vivía en nuestro país pero al margen de la constitución: una situación de no aplicación de las disposiciones controladoras de las iglesias y un paralelo alejamiento de éstas de los asuntos políticos. El tono normativo ha salido del estrecho campo de la separación Iglesia-Estado y "entra de lleno a la discusión sobre el Estado laico desde una perspectiva amplia de derechos humanos y diálogo democrático." (VALADEZ LÓPEZ, 2010, p. 17).

Muy Interesante es también el reconocimiento constitucional a la composición plural de la sociedad mexicana, específicamente a la población indígena. Asociado al levantamiento armado en contra del Estado mexicano por el denominado Ejército Zapatista de Liberación Nacional, que había emergido en enero de 1994, por reforma de 14 de agosto de 2001 se establecen principios constitucionales de reconocimiento y protección de la cultura y derechos de las comunidades indígenas y de sus miembros. Algunas áreas jurídicas de la vida indígena han sido afectadas positivamente a partir de esta disposición, especialmente el campo electoral en donde se admite el sistema de elecciones por usos y costumbres.

En materia económica puede mencionarse el decreto de 3 de febrero de 1983, que estableció el concepto de rectoría económica del Estado y fijó las áreas de interés público reservadas al Estado. Interesante posición en los albores del neoliberalismo mexicano. En el mismo campo, se inscribe la reforma de 6 de enero de 1992, que buscaba modernizar el régimen de propiedad agraria, facilitando el tránsito del régimen de propiedad comunitaria, 
esto es, ejidal y comunal, a propiedad privada. Asimismo, del 20 de agosto de 1993 es la gran reforma que otorga autonomía al banco central, lo que contribuyó, a la larga, de manera significativa a imprimirle estabilidad a la economía mexicana. Se agregan aquí las reformas en materia energética, especialmente las publicadas el 20 de diciembre de 2013, con las cuales se sustituye el sistema de monopolio legal en materia energética por uno en el cual los particulares nacionales o extranjeros participan en el desarrollo de esta industria, con lo cual ha sido superado otro gran principio del constitucionalismo mexicano que se refería al control por el Estado de los bienes asociados a la energía.

En cuanto a los derechos constitucionalmente establecidos, de las puntualizaciones que se han formulado se infiere algo muy claro, que es el crecimiento del número de derechos de 1917 a la fecha. Sobre el número de derechos que hoy contiene la Carta Magna en contraste con el texto original no es aquí posible cuantificarlo. Sólo de manera indicativa podemos recordar que mientras el texto de 1917 usó en 52 ocasiones la palabra "derecho", el texto vigente a septiembre de 2017 lo hace en 224 ocasiones. Ello de ninguna manera significa que cada vez que se utiliza el término derecho es que existe propiamente un derecho, sólo concluimos en el aumento de derechos constitucionalmente regulados.

El crecimiento y robustecimiento de los derechos constitucionalmente consagrados se puede conocer realmente a través del análisis de las variaciones de los textos constitucionales. Mencionamos aquí algunos ejemplos de derechos agregados al texto constitucional original, identificados más bien aleatoriamente de los registros de sus reformas. El derecho a la información se incorporó al texto constitucional en la reforma de 6 de diciembre de 1977. El derecho al voto de la mujer en toda la República lo fue en la reforma mencionada atrás de octubre de 1953. El derecho a la educación preescolar se incorpora al texto constitucional por reforma de 12 de noviembre de 2002. El de la educación media superior, el 9 de febrero de 2012. El derecho al agua el 8 de febrero de 2012. El derecho al medio ambiente sano el mismo 8 de febrero de 2012. El derecho a la alimentación nutritiva y de calidad en reforma de 13 de octubre de 2011. Los derechos de la niñez el 12 de octubre de 2011. El derecho a la cultura física y a la práctica del deporte, el 12 de octubre de 2011. El derecho de las víctimas de delito de resguardar su identidad y datos personales en reforma del 14 de julio de 2011. El de protección de datos personales, derecho al acceso, ratificación y cancelación de los mismos y a manifestar su oposición, en 1 de junio de 2009. El derecho de acceso a la cultura data de 30 de abril de 2009. El derecho de votar y ser votados en las comunidades indígenas, se incorpora por reforma de 22 de mayo de 2015. El derecho a buscar y recibir asilo se incorpora el 15 de agosto de 2016. El derecho a la identidad y al registro al momento del nacimiento es de 17 de junio de 2014, entre muchos más.

Reiteramos lo dicho con anterioridad sobre la centralidad de los derechos en el constitucionalismo mexicano contemporáneo. Esto permite contemplarlos en una categoría diversa de otros contenidos constitucionales. Considerando esta condición y el número importante de derechos, puede contemplarse una posible jerarquización interna del conjunto 
de derechos fundamentales. No existe formalmente alguna. Sin embargo, quizá podamos admitir que el propio texto constitucional ofrece una categoría específica de derechos con mayor fuerza constitucional, en el artículo 29 de la Carta Magna, al fijar aquellos derechos y libertades que ni siquiera en las situaciones de peligro grave puedan restringirse ni suspenderse, los cuales son, según el mencionado artículo, los derechos

[...] a la no discriminación, al reconocimiento de la personalidad jurídica, a la vida, a la integridad personal, a la protección a la familia, al nombre, a la nacionalidad; los derechos de la niñez; los derechos políticos; las libertades de pensamiento, conciencia y de profesar creencia religiosa alguna; el principio de legalidad y retroactividad; la prohibición de la pena de muerte; la prohibición de la esclavitud y la servidumbre; la prohibición de la desaparición forzada y la tortura; ni las garantías judiciales indispensables para la protección de tales derechos (CONSTITUCIÓN POLÍTICA DE LOS ESTADOS UNIDOS MEXICANOS, 1917, p. 40).

\section{BREVE RECAPITULACIÓN}

Con lo que hasta aquí se ha dicho es posible arribar a algunas cuestiones concluyentes sobre este siglo de constitucionalismo mexicano. Apuntamos algunos cambios y tendencias, y algunos comentarios procedentes.

\subsection{TRANSFORMACIÓN DESDE UN CONSTITUCIONALISMO PREDOMINANTE- MENTE INSTITUCIONAL, POLÍTICO, HACIA UNO QUE SE HA CENTRADO MÁS EN LOS DERECHOS HUMANOS}

Como apuntamos al principio de este ensayo, este parece ser el cambio de mayor profundidad de todos los que ha experimentado nuestra Constitución.

\subsection{CAMBIO DE UN CONSTITUCIONALISMO VOLCADO AL INTERIOR A OTRO VINCULADO AL CONTEXTO INTERNACIONAL}

Esta es una consecuencia de la transformación señalada en el punto anterior. Nuestro constitucionalismo, al estar centrado en los derechos humanos y al establecer, a partir de la reforma de 2011, la complementariedad entre los derechos humanos consagrados en la propia Constitución y los que se encuentran establecidos en los tratados internacionales y, en general dentro del Derecho internacional, conlleva la consecuencia de una importante integración de los contenidos de ambos órdenes normativos, el nacional y el internacional, en materia de derechos humanos.

\subsection{MUTACIÓN DE UN RÉGIMEN AUTORITARIO CON TENDENCIAS CORPO- RATIVISTAS A OTRO DEMOCRÁTICO}

En el texto se ha abundado sobre esta importante transformación del constitucionalismo mexicano. 


\subsection{TENDENCIA CLARA A UN CENTRALISMO NORMATIVO}

El estudio de las reformas constitucionales permite observar que en los últimos años se ha intensificado el proceso de centralización del Estado mexicano, a través de la incorporación a la Constitución de diversos contenidos. La tendencia afecta la distribución de competencias en el sistema federal. La centralización opera al menos de tres maneras diferentes. La primera consiste en el otorgamiento constitucional al Congreso de la Unión de facultades expresas para legislar en materias que antes no tenía, por ejemplo, en la facultad de emitir la legislación procesal penal en general, a nivel nacional, de 8 de octubre de 2013, o, en el mismo ámbito penal, la regulación de la justicia penal para adolescentes, en reforma de 2 de julio de 2015, o en materia de desaparición forzada de personas, en el decreto reformatorio de 10 de julio de 2015.

La segunda manera de afectar la legislación estatal y, por ende, impactar en la estructura competencial del federalismo mexicano, se observa en el comportamiento del revisor constitucional cuando señala a los legisladores de las entidades federativas, desde la propia Constitución, la obligación de incorporar en su correspondiente legislación estatal determinados contenidos normativos.

Finalmente, otra manera de centralizar la función normativa consiste en la atribución de facultades al Congreso de la Unión para emitir las bases a fin de que las legislaturas de las entidades federativas emitan sus correspondientes leyes en determinadas materias, o bien que el Congreso de la Unión determine en las leyes los espacios normativos que, en alguna determinada materia, comparten el Congreso de la Unión y las entidades federativas. Hoy en día a esta clase de legislación se le denomina leyes generales, y el órgano constituyente revisor le ha venido otorgando al Poder Legislativo Federal, con intensidad mayor en los últimos años, la facultad de emitir leyes generales en muchos ramos distintos. Se observa que, a septiembre de 2017, existen 46 leyes generales en el espacio normativo federal. Algunas de ellas no distribuyen competencias entre la Federación y las entidades federativas -de hecho, las más antiguas-, pues la materia regulada ya es nacional, como es el caso de la legislación en materia mercantil, pero sí la gran mayoría. Lo sorprendente es que 36 de ellas fueron emitidas en los últimos 15 años, lo cual permite inferir el creciente proceso de centralización normativa. ${ }^{22}$

\subsection{TRÁNSITO DESDE UN CONSTITUCIONALISMO ORIENTADO AL CONTROL DE LA ECONOMÍA HACIA UNO DE CONTENIDO NEOLIBERAL}

El de 1917 fue un constitucionalismo protector de los intereses económicos del Estado al proclamar la propiedad originaria de la Nación. Al día de hoy se encuentra muy distante de aquella filosofía. Desde las décadas de los ochentas se incorporaron reglas orientadas al fomento de la economía de mercado y a la participación de los particulares y las empresas en muchas áreas que se habían mantenido alejadas de las manos privadas, tales como el servicio público de la banca y el crédito en donde el decreto de 27 de junio de 1990 volvió a permitir la participación de los particulares. Asimismo el giro importante en la regulación de la propiedad agraria, específicamente la denominada propiedad comunitaria de ejidos y comunidades indígenas, en la reforma de 6 de enero 
de 1992. Al mismo tiempo, desaparecieron del ámbito de acción estatal muchas empresas públicas en la década de los ochentas y los noventas, y más recientemente se han liberado importantes sectores asociados tradicionalmente al Estado corporativista y controlador de la economía, como PEMEX.

\subsection{PROLIJIDAD EN LOS CONTENIDOS DE LA CONSTITUCIÓN}

El nivel de detalle normativo en las disposiciones constitucionales a que se ha arribado por el crecimiento de la densidad narrativa de la Constitución genera varias consecuencias, por ejemplo, puede conducir a la incorporación de reglas que obedecen a criterios políticos circunstanciales o políticas francamente equivocadas, las cuales, al cambiar las circunstancias, conducen a nuevas reformas. Ejemplos hay varios, como fue el caso de la reforma constitucional de 22 de enero de 1927 mediante la cual se permitió constitucionalmente la reelección mediata del presidente, que fue suprimida por decreto de 29 de abril de 1933. Otro caso es el de la mal denominada "nacionalización de la banca", estatuida por reforma de 17 de noviembre de 1982, que fue revertida por diverso decreto de 27 de junio de 1990.

La prolijidad de los contenidos constitucionales se ha extendido al ámbito de los denominados artículos transitorios o "régimen de transitoriedad". Se encuentran en algunas de las reformas constitucionales un elevado número de disposiciones "transitorias" cuya causa puede estar asociada a una actitud estratégica de los legisladores constitucionales. Algunos ejemplos de esta extensión grande de los artículos transitorios son el decreto de 27 de mayo de 2015, sobre combate a la corrupción, que cuenta con 11 artículos transitorios. También el diverso decreto de 10 de febrero de 2014, abordando la materia político electoral, con 21 artículos de este carácter, y el publicado el 11 de junio de 2013, cuya materia fue la reforma de telecomunicaciones, con 19 artículos transitorios. Parece descubrirse una estrategia legislativa del reformador constitucional en esta profusión de normas transitorias porque se consigue un doble efecto mediante esto, ya que esas disposiciones no sólo señalan líneas de legislación claras al legislador o legisladores que deben desarrollar las disposiciones constitucionales correspondientes, sino que, además, los jueces encargados del control de constitucionalidad han señalado que los decretos de reforma constitucional no son objeto de control por vías jurisdiccionales, escapando de esta manera de dicho control también los contenidos de los transitorios.

\section{ALGUNAS APRECIACIONES FINALES}

En un escenario de modificaciones formales a la Constitución en crecimiento, de democracia viva pero todavía no consolidada, de insuficiencia de controles sobre los poderes pero ya instituciones en diálogo, de urgencias para hacer transparente el ejercicio del poder, de falta de rendición de cuentas, de irresponsabilidad de actos ilegales cometidos por servidores públicos, de insuficiencia de satisfactores sociales en materia educativa y de salud, en fin, de muchas carencias, puede pensare que la agenda para el constitucionalismo mexicano sería hoy muy grande.

Durante muchas décadas, el órgano reformador mexicano fue el intérprete fundamental de la relación entre Constitución y sociedad, entre derecho y realidad. Este ensayo centró 
su atención en el desarrollo de la Constitución como el legado del intérprete político de la realidad y su actuación en los cien años de constitucionalismo mexicano. La mirada retrospectiva de este constitucionalismo deja el sabor de un derecho muy dinámico que dialoga con una sociedad en movimiento muy intenso. En este diálogo la constitución es reflejo de una sociedad en mutación pero también causa de otros cambios sociales. La acción continua y creciente del revisor constitucional ha incorporado otras opciones para crear realidades a partir de las nuevas normas. Es parte del carácter del constitucionalismo mexicano.

Pero, al mismo tiempo, los signos de los tiempos apuntan, a través de la juridificación creciente de la constitución, a centrar el texto constitucional en los derechos humanos y a acrecentar la posición de los jueces. Esta ha sido también la experiencia del constitucionalismo mexicano desde 1994. De la mano de las transformaciones mayores que en esto hemos vivido se incorporan discusiones sobre teorías influyentes que debaten la constitucionalización de los órdenes jurídicos como el neoconstitucionalismo o el garantismo o las teorías procedimentalistas o las de los valores o principialistas. ${ }^{23}$

La escueta narración ofrecida de nuestra historia constitucional centenaria concluye en una situación de diálogos entre políticos y jueces. Estos diálogos deben hacerse en el contexto propio de nuestro constitucionalismo, esto es, con las reglas y las costumbres admitidas en la cultura constitucional actual. Es dentro de ellos donde deben atenderse las asignaturas pendientes que puedan encontrarse. Consolidar la democracia, crear una cultura constitucional sólida, superar los grandes desequilibrios sociales, fortalecer el estado de derecho, construir una sociedad participativa e informada son algunos reclamos que pueden dirigirse al constitucionalismo, aunque estamos avanzando en estos senderos. Pero es verdad que no son cuestiones sólo de instituciones, de tribunales constitucionales y de legisladores constitucionales. El tema está también en la sociedad participativa, por lo que retoma sentido la exigencia de quienes abogan por fortalecer la democracia y el estado de derecho. Avanzar en constitucionalizar la política y constitucionalizar al derecho, en lograr una capacidad evolutiva de la constitución, de sus reformas y adiciones, y de sus interpretaciones.

\section{THE LEGACY OF THE CONSTITUENTS OF QUERETARO: PROGRESS AND AGENDA}

\section{ABSTRACT}

In the light of the Mexican Constitution centennial and thus hundred years of its validity since it was first published in the city of Queretaro on February $5^{\text {th }}$ of 1917, this essay analyzes the evolution of Mexican constitutionalism. It sustains that the longevity of the Constitution is due to the intense activity of the Legislative power in charge of reforms and constitutional amendments, which have made it possible for the adaptability of the Constitution vis-à-vis the evolution of Mexican society. But, at the same time, this has contributed for Mexican constitutionalism to have a better understanding of the Constitution from a formal legal perspective that goes together with that political one. Therefore, in this new understanding of Mexican constitutionalism, the coexistence of a political perspective -whereas the amendments formally adapt the Constitution 
to a certain reality- and a crescent judicial and legal perspective -whereas the Judicial power is in charge of the legal interpretation of the Constitution- creates an environment of constitutional dialogue between the amendment function and the judicial review, between legislators and judges.

Keywords: Legal History. Constitutional Law. Constitutional Reform. Mexican Constitution. Federalism. Judicial Review.

\section{O LEGADO DOS CONSTITUINTES DE QUETARO: PROGRESSOS E PROGRAMAS}

\section{RESUMO}

Este ensaio trata da análise da evolução do constitucionalismo mexicano ao se completar cem anos de vigência da Constituição mexicana, que foi promulgada na cidade de Queretaro em 5 de Fevereiro de 1917. O ensaio argumenta que a longevidade desta Constituição se deve à intensa atividade dos órgãos legislativos mexicanos no exercício da função de reforma constitucional, que tem contribuído para uma grande plasticidade do texto escrito, favorecendo a adaptação entre a norma fundamental e a evolução da sociedade mexicana. Ao mesmo tempo, o desenvolvimento do constitucionalismo mexicano, que historicamente privilegiava o olhar político dos órgãos legislativos acima mencionados, levou a um fortalecimento do entendimento jurídico da Constituição. Isto leva a admitir - em uma nova compreensão do constitucionalismo mexicano - a coexistência entre o entendimento político tradicional, que age por meio de ajustes formais ao texto constitucional, com uma presença crescente dos órgãos judiciais que imprimem viés claramente legal para a Constituição Mexicana, criando com ela um ambiente de diálogos constitucionais entre as funções da reforma constitucional e o controle da regularidade constitucional.

Palavras-chave: História Jurídica. Direito constitucional. Reforma constitucional. Constituição Mexicana. Federalismo. Controle Constitucional.

1 Véase Aguiló Regla (2007, p. 21- 23), como lo dice expresamente el autor "(1)as distintas concepciones de constitución lo que hacen es tomar una o varias propiedades de la constitución y elevarlas a la categoría de propiedades 'rectoras' de esa constitución [...] no versan sobre las propiedades que caracterizan a una constitución, sino sobre la preeminencia de unas sobre otras."

2 Véase, Rabasa (1968); revísese, en particular, el Capítulo V. "La obra del constituyente", con ácidas críticas a la carencia de correspondencia entre el texto constitucional de 1857 y la realidad social que regulaba.

3 Véase el Discurso de Venustiano Carranza, Primer Jefe del Ejército Constitucionalista, al abrir el Congreso Constituyente, en su sesión del $1^{\circ}$ de diciembre de 1916 (MÉXICO, 1916).

4 Ibidem.

5 Así lo indica el profesor Córdova (1973) en su excelente obra La ideología de la Revolución Mexicana.

6 Véase el puntual análisis sobre estos temas en Cossío Díaz (1998).

7 La vieja doctrina medieval de la teocracia pontifical daba sustento legitimador a los poderes de los monarcas españoles y de otros reinos cristianos. Esta doctrina consistía en la aceptación de la facultad papal para otorgar el dominio de las tierras y aguas a los príncipes católicos, en tanto ellos asumieran la obligación de propagar la fe 
cristiana. La tesis era comúnmente admitida aunque tenía un sustento muy frágil pues se apoyaba en un ancestral documento considerado apócrifo, de los orígenes del cristianismo, que databa del siglo IV. Véase Küng (2014).

8 Por ejemplo, véase Cossío Díaz (1998).

9 Véase Hesse (1983, p. 22).

10 Véase <http://www.diputados.gob.mx/LeyesBiblio/ref/cpeum.htm>.

11 Véase Raigosa (2017, p. 68 y ss).

12 Ibidem.

13 Sobre esto, véase con mayor detalle a Raigosa (2017, p. 68 y ss).

14 Esta disposición es antigua, proviene del artículo 126 de la Constitución de 1857.

15 Cuadro elaborado por el autor, con apoyo de Alan Yavé Cortés Juárez, con información de la página de la Cámara de Diputados, en <http://www.diputados.gob.mx/LeyesBiblio/ref/cpeum_crono.htm>, y <http:// www.diputados.gob.mx/LeyesBiblio/ref/cpeum_per.htm>.

16 Véase, en general, Meyer (1994). Este autor sostiene que la guerra cristera puede ser vista como la etapa final de la Revolución Mexicana.

17 Véase Meyer (2010, pp. 225 y ss).

18 A menos que se diga otra cosa, todos los textos de los decretos de reforma constitucional que aquí son mencionados fueron consultados en la página de la Cámara de Diputados con la dirección siguiente: <http://www. diputados.gob.mx/LeyesBiblio/ref/cpeum_crono.htm $>$.

19 Véase, Cossío Díaz (2001, pp. 25 y ss).

20 Sobre este asunto, véase Benítez Tiburcio (2008), en especial el Capítulo IV. Cuestiones de justicia electoral.

21 Ibidem, véase particularmente el Capítulo III. La reforma constitucional de 2007.

22 Entre ellas, están la Ley general en materia de resolución de controversias, con excepción de la materia penal; la Ley general en materia de registros civiles; la Ley general en materia de reforma regulatoria; la Ley general en materia de justicia cívica e itinerante; la Ley general en materia de derechos de las víctimas; la Ley general de responsabilidades administrativas; la Ley de bases de endeudamiento de autoridades de entidades federativas y municipios; la Ley general en materia de partidos políticos federales y locales; la Ley general de instituciones y procedimientos electorales; la Ley general sobre el sistema nacional de archivos, la Ley general en materia de transparencia; la Ley general en materia de protección de datos; la Ley general de registros públicos inmobiliarios, de personas y de catastro (no emitida todavía); la Ley que establece las bases de coordinación en materia de delincuencia organizada; la Ley general de contabilidad gubernamental.

23 Entre las obras de mayor influencia y algunos protagonistas de estas construcciones teóricas se encuentran las siguientes: por orden alfabético, Ackerman (1993), Dworkin (1988), Ely (1981), Ferrajoli (2000), Fiss (1986), Zagrebelsky (1995).

\section{REFERENCIAS}

ACKERMAN, Bruce. We the people: foundations. Cambridge: The Belknap Press of Harvard University Press, 1993.

AGUILÓ REGLA, Josep. Cuatro pares de concepciones opuestas de la Constitución. En:

AGUILÓ REGLA, Josep; ATIENZA, Manuel; MANERO, Juan Ruiz. Fragmentos para una teoría de la Constitución. Madrid: Iustel, 2007.

ARAGÓN REYES, Manuel. La Constitución como paradigma. En: EL SIGNIFICADO actual de la constitución: memoria del Simposio internacional. México: UNAM, 1998. p. 19-32. Disponible en: < https://biblio.juridicas.unam.mx/bjv/detalle-libro/130-el-significado-actual-de-la-constitucion-memoria-del-simposio-internacional\#5606>. Acceso en: 31 agosto 2017. 
BENÍTEZ TIBURCIO, Alberto et al. La reforma constitucional en materia electoral de 2007. México: Senado de la República-ITAM, 2008.

CABRERA ACEVEDO, Lucio. La Suprema Corte de Justicia durante el gobierno del General Lázaro Cárdenas (1935-1940). Parte I. México: [s.n.], 1999. Disponible en: <http:// sistemabibliotecario.scjn.gob.mx/sisbib/CST/26881/26881.pdf>. Acceso em: 17 sept. 2017. CIUDAD DE MÉXICO. Cámara de Diputados. Reformas Constitucionales por Decreto en orden cronológico. Disponible en: <http://www.diputados.gob.mx/LeyesBiblio/ref/ cpeum_crono.htm $>$. Acceso em: 15 sept. 2017a.

CIUDAD DE MÉXICO. Cámara de Diputados. Reformas Constitucionales por Periodo Presidencial. Disponible en: <http://www.diputados.gob.mx/LeyesBiblio/ref/cpeum_per. htm >. Acceso em: 15 sept. $2017 \mathrm{~b}$.

CÓRDOVA, Arnaldo. La ideología de la Revolución Mexicana. México: Ediciones ERA-IIS/UNAM, 1973.

COSSÍO DÍAZ, José Ramón. Las concepciones del derecho en el constituyente de 19161917. Anuario Mexicano de Historia del Derecho, México, v. 10, p. 193-205, 1998. Disponible en: <https://revistas-colaboracion.juridicas.unam.mx/index.php/anuario-mexicano-historia-der/article/view/29572>.

. Cambio social y cambio jurídico. Porrúa, México: ITAM-M. A., 2001.

DE VEGA GARCÍA, Pedro de Vega. La reforma constitucional como defensa de la constitución y la democracia. En: JORNADAS DE DERECHO CONSTITUCIONAL SOBRE LA REFORMA DE LA CONSTITUCIÓN, 2., 2006, España. Fundación Manuel Giménez Abad de Estudios Parlamentarios y del Estado Autonómico. Disponible en: <https://dialnet.unirioja.es/servlet/autor?codigo=26409>. Acceso en: 9 Sept. 2017.

DWORKIN, Ronald. El imperio de la justicia. Barcelona: Gedisa, 1988.

ELY, John Hart. Democracy and Distrust. Cambridge: Harvard University Press, 1981. FERRAJOLI, Luigi. Derecho y razón: teoría del garantismo penal. Prólogo de Norberto Bobbio. 4. ed. Madrid: Trotta, 2000.

FISS, Owen. Objectivity and Interpretation, Stan. L. Review, v. 34, p. 763-739, 1986.

HESSE, Konrad. Escritos de Derecho constitucional. Madrid: Centro de Estudios Constitucionales, 1983.

INSTITUTO NACIONAL ELECTORAL. Vot y elecciones: resultados electorales. Disponible en: <https://www.ine.mx/voto-y-elecciones/resultados-electorales/>. Acesso em: 15 sept. 2017.

KÜNG, Hans. La Iglesia Católica. Traducción Alberto Borrás. 2. ed. México: Debolsillo, 2014. MEYER, Jean. La cristiada 1: la guerra de los cristeros. Mexico: Siglo Veintiuno Editores, 1994. Disponible en: <https://books.google.cl/books?id=xqhbJ3GZ8X4C\&printsec $=$ fron tcover\&hl=es $\#_{\mathrm{v}}=$ onepage $\& \mathrm{q} \& \mathrm{f}=$ false $>$. 
. La Revolución mexicana. [S.1.]: Maxi Tusquets editores, 2010.

MÉXICO. Suprema Corte de Justicia de la Nación. Discurso de Venustiano Carranza, Primer Jefe del Ejército Constitucionalista, al abrir el Congreso Constituyente, en su sesión del $1^{\circ}$ de diciembre de 1916. Disponible en: <https:/www.sitios.scjn.gob.mx/constitucion1917-2017/ sites/default/files/CPEUM_1917_CC/DVC_1916.PDF>. Acceso en: 7 sept. 2017.

MÉXICO. Constitución Política de los Estados Unidos Mexicanos. Diario Oficial de la Federación, 5 de febrero de 1917. Última reforma publicada DOF 15-09-2017. Disponible en: <https://mexico.justia.com/federales/constitucion-politica-de-los-estados-unidos-mexicanos/titulo-septimo/\# articulo-133>.

MÉXICO. Cámara de Diputados. Listados de legislaturas: LXIII Legislatura. Disponible en: < http://gaceta.diputados.gob.mx/SIL/Legislaturas/Listados.html>. Acesso em: 15 sept. 2017.

MOLINA ENRÍQUEZ, Molina. [La ideología de la Revolución Mexicana]. En: CÓRDOVA, Arnaldo. La ideología de la Revolución Mexicana. México: Ediciones ERA-IIS/UNAM, 1973.

RABASA, Emilio. La constitución y la dictadura: estudio sobre la organización política de México. 4. ed. México Porrúa, 1968.

RAIGOSA, Luis. Control de la regularidad constitucional (constitucionalidad y convencionalidad). En: EL PODER Judicial de la Federación y los grandes temas del constitucionalismo. Ciudad de México: Secretaria de Cultura, 2017. p. 65-104. Disponible en: <https://archivos.juridicas.unam.mx/www/bjv/libros/9/4427/14.pdf>.

RAIGOSA, Luis. Las Funciones legislativas y no legislativo del Senado. México: Senado de la República-ITAM-Miguel Ángel Porrúa, 2008.

ROUAIX, Pastor. [Forjadores de la Revolución Mexicana]. En: BOJORQUEZ, JUAN DE DIOS. Forjadores de la Revolución Mexicana. México: Instituto Nacional de Estudios Históricos de la Revolución Mexicana, 1960. Tomo I. Disponible en: <http://www.bicentenario.gob.mx/bdb/bdbpdf/ForjadoresDeLaRevolucionMexicana_Tomo-I/ForjadoresDeLaRevolucionMexicana_Tomo-I-pastorRouaix.pdf>. Acceso en: 8 Sept. 2017.

ROUAIX, Pastor. Artículo 27. En: CÓRDOVA, Arnaldo. La ideología de la Revolución Mexicana. México: Ediciones ERA-IIS/UNAM, 1973.

VALEDEZ LÓPEZ, Vanessa. Laicidad en la Constitución Política de los Estados Unidos Mexicanos. Ensayo para obtener el título de licenciada en Derecho. México: ITAM, 2010. ZAGREBELSKY, Gustavo. El derecho dúctil. Ley, derechos, justicia. Traducción de Marina Gascón Abellán. Madrid: Trotta, 1995. 